\title{
Entrevista com Garry Herrigel
}

\author{
Gabriela Lanza PORCIONATO*
}

\section{Contexto da Entrevista}

Garry Herrigel concedeu a entrevista a Gabriela Lanza Porcionato por e-mail, em dezembro de 2020, em meio às medidas de restrição de contato social impostas pela pandemia da Covid-19. A conversa versa sobre carreira acadêmica, sociologia econômica, influência da sociologia econômica americana e consequências sociais da pandemia da Covid-19.

\section{Apresentação do entrevistado}

Gary Herrigel é Professor na Faculdade e Divisão de Ciências Sociais do Departamento de Ciência Política da Universidade de Chicago ${ }^{1}$. Herrigel se interessa pelas temáticas de economia política comparativa, organizações e formas alternativas de governação no mundo desenvolvido e em desenvolvimento, e tem publicado sobre mudanças industriais e desenvolvimento econômico na Europa, Estados Unidos, Japão e China. O seu trabalho é qualitativo, combinando análise histórica, etnografia, relacional e processual.

As publicações acadêmicas se estendem por uma variedade de disciplinas, incluindo sociologia, estratégia empresarial, história empresarial, relações industriais, estudos de regulação, geografia econômica e economia política comparativa. $\mathrm{O}$ traço comum nas pesquisas e análises desenvolvidas por Herrigel tem sido o inte-

\footnotetext{
UNESP - Universidade Estadual Paulista "Júlio de Mesquita Filho". Faculdade de Ciências e Letras de Araraquara. Programa de Pós-Graduação em Ciências Sociais. Araraquara - SP - Brasil. 14800901 - gabiporcionato@gmail.com. https://orcid.org/0000-0002-0231-536X.

1 The Department of Political Science. The University of Chicago. Diponível em: https://political-science. uchicago.edu/directory/gary-herrigel. Acesso em: 15 abr. 2021.
} 
resse nas mudanças nas fronteiras e nos inter-relacionamentos entre as empresas de manufatura na Europa (especialmente na Alemanha), América do Norte e Ásia, com foco nos arranjos sociais e políticos que governam o comportamento e a estratégia da empresa e que afetam (e organizam) a competitividade, a capacidade inovadora, as relações de trabalho e as condições de trabalho.

Entre 2017 e 2018, Herrigel foi presidente da Society for the Advancement of Socio-Economics (SASE), uma organização acadêmica internacional interdisciplinar, incluindo disciplinas como economia, sociologia, economia política, ciência política, estudos de organização, administração, psicologia, direito e história.

Gabriela Porcionato: Gostaria de começar a entrevista com o tema que me levou a Chicago, a internacionalização ${ }^{2}$. Imagino que a internacionalização também é interesse do Professor, visto que realizou pesquisas na China e na Alemanha. Professor, poderia relatar como surgiu o interesse em estudar realidades/sociedades fora dos EUA? Poderia descrever como foi o processo de inserção nesses dois países, a formação de redes de contatos, as facilidades e dificuldades de estar e escrever sobre esses países? Quais as experiências marcantes e desafiadoras?

Garry Herrigel: Fiz o meu doutoramento nos anos 1980 e desenvolvi o tema da minha dissertação no início dessa década. Foi o auge da revolução Reagan - Thatcher no Ocidente. As forças conservadoras tinham lançado uma ofensiva muito agressiva contra o trabalho organizado. Além disso, a indústria norte-americana estava sob pressão das importações alemãs e japonesas. Por razões pessoais e familiares, tinha alguma capacidade de falar a língua alemã. Um estudo da indústria alemã parecia muito importante nessa altura. Ao contrário dos argumentos dos conservadores, os alemães eram fabricantes altamente competitivos com sindicatos muito fortes, muitos trabalhadores qualificados e salários elevados. Estava determinado a descobrir como tudo isso era possível e a contrariar muitos dos argumentos antissindicalistas que prevaleciam nos EUA naquela época. $\mathrm{O}$ meu primeiro livro, Industrial Constructions. The Sources of German Industrial Power, foi o resultado desse interesse.

Gabriela Porcionato: Na entrevista conduzida por Georg Rilinger, em fevereiro de 2018, quando era presidente da SASE, você menciona: "Eu sempre fui um mau cientista político". Poderia explicar mais sobre isso?

\footnotetext{
2 Herrigel foi co-orientador estrangeiro durante minha estadia nos Estados Unidos através do Programa Doutorado Sanduiche no Exterior (PDSE) 2019/2020.
} 
Gary Herrigel: Com isso quis simplesmente dizer que sempre me interessei mais pela forma como as variáveis políticas ajudam a moldar e até constituírem atores econômicos, empresariais e sindicais. Os "bons" cientistas políticos têm a política como variável dependente. Eu tinha a política como a minha variável independente.

Gabriela Porcionato: Poderia apontar alguns professores e autores que o inspiraram quando era estudante e que afetaram diretamente a sua trajetória e investigação, especialmente o carácter interdisciplinar e internacional?

Gary Herrigel: Os professores mais imediatamente influentes no meu desenvolvimento foram Charles Sabel ${ }^{3}$ e Joshua Cohen ${ }^{4}$. Mais remotamente, mas ainda extremamente importantes, foram Michael Piore ${ }^{5}$, Horst Kern ${ }^{6}$, Michael Schumann ${ }^{7}$ e Jonathan Zeitlin ${ }^{8}$. Uma vez na Universidade de Chicago, fui muito influenciado pelo trabalho e amizade dos meus colegas Andrew Abbott ${ }^{9}$, Moishe Postone ${ }^{10} \mathrm{e}$ John Padgett ${ }^{11}$. Um pouco mais distante, mas ainda bastante significativo, aprendi com o trabalho da minha colega Karin Knorr Cetina ${ }^{12}$. Ultimamente, para além de todas essas pessoas, alguns dos meus colegas mais jovens aqui em Chicago têm

\footnotetext{
3 Charles Fredrick Sabel é professor de Direito e Ciências Sociais na Columbia Law School. Suas pesquisas se concentram em inovações públicas, governança da União Européia, normas trabalhistas, desenvolvimento econômico e redes ultra robustas.

4 Joshua Cohen é um filósofo estadunidense, especializado em filosofia política. Ele lecionou na Universidade de Stanford e no Instituto de Tecnologia de Massachusetts.

5 Michael Joseph Piore é economista estadunidense, professor de economia e ciência política no Instituto de Tecnologia de Massachusetts.

6 Horst Kern é cientista social alemão, professor emérito da Georg-August-Universität Göttingen.

7 Michael Schumann foi um professor aposentado de filosofia alemão que se tornou um defensor da reforma na Alemanha Oriental e um político durante os preparativos para a reunificação alemã. Ele é visto como pioneiro do Partido do Socialismo Democrático, que substituiu o Partido da Unidade Socialista na República Democrática Alemã em 1989/90.

8 Professor de Políticas Públicas e Governança do Departamento de Ciência Política da Faculdade de Ciências Sociais e Comportamentais da Universidade de Amsterdã. Lecionou na Universidade de Wisconsin-Madison, como Professor de Sociologia, Políticas Públicas, Ciência Política, Relações Industriais e História.

9 Andrew Delano Abbott sociólogo e teórico social americano. Seus tópicos de pesquisa variam de ocupações e profissões à filosofia dos métodos, à história das disciplinas acadêmicas e à sociologia do conhecimento.

${ }^{10}$ Moishe Postone foi um teórico crítico e professor de história na Universidade de Chicago. Era conhecido tanto por sua interpretação do antissemitismo moderno quanto por sua reinterpretação da teoria crítica marxiana.

11 John Padgett é professor especializado em política americana, teoria organizacional, modelos matemáticos e políticas públicas.

12 Karin Knorr Cetina é uma socióloga austríaca conhecida por seu trabalho em epistemologia e construcionismo social. Ela se concentra no estudo de microestruturas globais e estudos sociais de finanças.
} 
sido muito inspiradores para mim, em particular os historiadores Paul Cheney ${ }^{13}$, e Jonathan Levy ${ }^{14}$.

Gabriela Porcionato: Quando eu era visitante na Universidade de Chicago, sob a sua supervisão, participei em dois workshops de grupos de investigação, Money, Markets, and Governance (MMG) na Business School e History of Capitalism, no Departamento de Ciências Sociais. No início, podia-se considerá-los antagônicos, mas na realidade eram interdisciplinares e um esforço no sentido de colmatar a lacuna entre História, Sociologia e Economia. Você se percebe como um estudioso interdisciplinar? Como isso afeta o seu ensino? Como investigador, supervisor e professor, tem uma abordagem interdisciplinar com os seus alunos? O que procura despertar?

Gary Herrigel: Recebi formação em um programa interdisciplinar no MIT: O Programa de Estudos de Ciência, Tecnologia e Sociedade. O meu trabalho sempre cruzou as fronteiras entre ciência política, sociologia, geografia econômica, história (especialmente história empresarial) e estratégia empresarial. Isto faz de mim um mau cientista político. Há muito a dizer a favor de um enfoque disciplinar e eu, na minha velhice, passei a acreditar mais do que na minha juventude, que é importante que os jovens estudiosos sejam formados de forma bastante intensiva em uma determinada disciplina. Mas a interdisciplinaridade mantém as pessoas honestas e obriga-as a pensar sobre as coisas a partir de uma perspectiva diferente.

Gabriela Porcionato: A SASE tem também um carácter interdisciplinar, proporcionando uma miríade de debates, temas e abordagens. O que mais admira na SASE e o que mais chamou sua atenção nas últimas conferências? O que vê como seu legado como presidente da SASE? Poderia indicar alguns caminhos seguidos pela SASE, o que mudou ao longo do tempo e o que ficou? Como é que cresceu e se desenvolveu ao longo do tempo?

Gary Herrigel: A SASE é uma organização maravilhosa com uma história muito interessante. Foi fundada e serviu durante muitos anos como uma saída para acadêmicos que trabalhavam em questões econômicas, empresariais e laborais que não se enquadravam bem nos limites da ciência política e sociologia. Hoje, à medida que a economia política e a sociologia econômica se tornaram bem enraizadas

\footnotetext{
${ }_{13}$ Paul Cheney é um historiador da Europa com especialização no antigo regime da França e seu império colonial. Possui como campo de interesse: História francesa; o lluminismo; a revolução Francesa; o mundo atlântico; história do pensamento político; e o capitalismo moderno inicial.

${ }^{14}$ Professor de História dos Estados Unidos, Fundamentos, Pensamento Social, historiador da vida econômica e dos Estados Unidos, com interesses nas relações entre história dos negócios, economia política, história do direito e história das ideias e cultura.
} 


\section{Entrevista com Garry Herrigel}

em disciplinas estabelecidas, a SASE tornou-se mais corrente. É especialmente importante para os sociólogos econômicos. O meu mandato como presidente foi marcado de forma mais acentuada por movimentos no sentido de criar mais diversidade na associação, especialmente em termos de gênero. Mas também realizamos a nossa primeira conferência na Ásia quando eu era presidente. Foi um passo importante para a associação.

Gabriela Porcionato: Podemos dizer que uma rede internacional de investigadores de sociologia econômica existe há alguns anos. Como vê esta rede hoje? Como vê a sociologia econômica nos EUA, não só em termos teóricos, mas também em termos de rede de investigadores? E que tal outras abordagens, como a francesa? Quais são as divergências e convergências entre a sociologia econômica americana e europeia e/ou francesa? (Se, considerando que posso fazer esta generalização - usando a europeia e a francesa como sinônimos - seria possível universalizar e fazer uma oposição entre uma "sociologia econômica americana" e uma "sociologia econômica europeia"?

Gary Herrigel: A sociologia econômica americana tem sido influenciada de muitas maneiras pela sociologia econômica europeia, especialmente a escola de ator-rede na França e o trabalho neo-pragmático que está a ser realizado por Jens Beckert e os seus estudantes e colegas do Instituto Max Planck em Cologne ${ }^{15}$. David Stark ${ }^{16}$ na Columbia tem sido um forte transmissor dessas influências europeias para a cena americana. Mas a sociologia econômica americana tem muitos pontos fortes no trabalho histórico e institucional - por exemplo, Monica Prasad ${ }^{17}$, Greta Krippner ${ }^{18}$, Bruce Carruthers ${ }^{19} \mathrm{e}$ um pouco mais atrás, Margaret Somers ${ }^{20}$. Também, não subestimar a influência de longa data de várias formas de análise de redes na sociologia

\footnotetext{
15 Jens Beckert é, desde 2005, director do Max Planck Institute for the Study of Societies (MPIfG), Cologne, Alemanha. Instituto Max Planck para o Estudo de Sociedades (MPIfG) é uma instituição de pesquisa com foco nas conexões entre a ação econômica, social e política.

${ }^{16}$ David Charles Stark é Arthur Lehman professor de Sociologia na Universidade de Columbia, onde atuou como presidente do departamento de sociologia e dirige o Centro de Inovação Organizacional. Ele também é professor de Ciências Sociais na Universidade de Warwick.

${ }^{17}$ Monica Prasad é uma socióloga americana e ganhou vários prêmios por seus livros sobre sociologia econômica e política. Prasad é professora de sociologia na Northwestern University.

18 Greta Krippner é professora da Universidade de Michigan, socióloga da história com interesses em sociologia econômica, sociologia política, sociologia do direito e teoria social. Seu trabalho explora como a ascensão do mercado se cruzou com as transformações sociais, culturais e políticas na sociedade dos EUA ao longo século XX.

${ }^{19}$ Bruce G. Carruthers é professor de sociologia do Departamento de Sociologia da Universidade Northwestern, Chicago, Illinois, EUA. Tem como áreas de interesse: Sociologia Comparada, Economia e Sociedade, Sociologia do Direito, Sociologia das Organizações.

${ }^{20}$ Margaret R. Somers é uma socióloga americana, professora de Sociologia e História na Universidade de Michigan. Recebeu o prêmio inaugural Lewis A. Coser de Inovação e Definição de Agenda Teórica em Sociologia.
} 
econômica americana continua a ser extremamente importante - Woody Powell ${ }^{21}$, John Padgett. Também a teoria de campo (através do seu encontro com Bourdieu) continua a ser influente - o trabalho de Neil Fligstein é exemplar aqui ${ }^{22}$.

Gabriela Porcionato: Como vê o Brasil na rede global da sociologia econômica? Tem contato com a sociologia econômica brasileira? Considera estudar o Brasil na sua investigação internacional? Em caso afirmativo, poderia descrever um possível tema de interesse e as suas hipóteses?

Gary Herrigel: Aprendi muito com estudiosos brasileiros ao longo dos anos. Gabriela, você faz parte de uma longa linhagem de estudantes que vieram à Universidade de Chicago para uma visita de um ano. Atualmente, estou trabalhando com uma colega brasileira (que conheci durante os meus estudos de pós-graduação no MIT) sobre cadeias de abastecimento industrial e questões de desenvolvimento no setor petrolífero no Brasil. O Brasil é um país enormemente rico e importante onde questões fundamentais sobre desenvolvimento, equidade e ambiente estão a ser colocadas e a debater-se neste momento. É essencial ter intercâmbios com estudiosos brasileiros e apoiar o trabalho contemporâneo no Brasil neste momento da história mundial.

Gabriela Porcionato: No seu segundo livro, Manufacturing Possibilities (2010), você estudou o período da Segunda Guerra e o processo de recomposição; ou seja, um período de crise. Não queremos forçar um caráter premonitório, mas, com a crise do coronavírus (COVID-19), quais são as suas preocupações e impressões sobre um possível processo de recomposição nos vários segmentos da sociedade?

Gary Herrigel: Oh, essa é uma grande questão! Ainda estamos muito no meio das coisas. Mas o meu sentido é que haverá uma recomposição mais profunda na estrutura das trocas e especializações globais à medida que a sociedade global sair da crise da Covid-19. O imaginário Ricardiano que o neoliberalismo gerou para compreender as especializações e o desenvolvimento global foi seriamente posto em causa pela crise do coronavírus. O meu sentimento é que haverá maiores lutas entre estados para se afastarem das fortes formas de especialização nacional que foram fomentadas pela propagação das cadeias de abastecimento global a partir do Norte. Isso não significa que não haverá comércio ou outras formas

\footnotetext{
${ }^{21}$ Professor de Educação e (por cortesia) Sociologia, Comportamento Organizacional, Ciência e Engenharia de Gestão e Comunicação na Universidade de Stanford.

${ }_{22}$ Neil Fligstein é sociólogo americano e professor da Universidade da Califórnia, Berkeley, conhecido por seu trabalho em sociologia econômica, sociologia política e teoria organizacional. Para mais recomenda-se FLIGSTEIN, Neil. Habilidade social e a teoria dos campos. Rev. Adm. Empres., São Paulo, v. 47, n. 2, p.61-80, June, 2007.
} 


\section{Entrevista com Garry Herrigel}

de intercâmbio global. Mas, na minha opinião, o desenvolvimento a avançar terá de ser mais diversificado e mais sustentável do ponto de vista ambiental. Pessoalmente, penso também que as fronteiras herdadas em matéria de emprego que temos entre indústria, agricultura e serviços terão de ser recalibradas. Temos tanto subemprego em âmbito mundial enquanto os produtores, tanto na agricultura como na indústria, têm seguido estratégias de escala que limitam sistematicamente a quantidade de pessoas que empregam. Isto seria uma coisa atrativa se os aumentos de produtividade e produção que essas estratégias gerassem maiores rendimentos, maior bem-estar, e um ambiente saudável. Mas em vez disso parecem ter gerado formas cada vez mais grotescas de desigualdade, subemprego e, no caso da agricultura, uma enorme degradação ambiental. Estas características da vida moderna não me parecem sustentáveis política, econômica, social e ecologicamente.

Gabriela Porcionato: O que os leitores encontrão no artigo Industrial possibilities and false necessity: rethinking production, employment and labor dynamics in the global economy ${ }^{23}$, publicado em 2020 pela Socio-Economic Review e que está em processo de tradução para o português? Poderia fazer o exercício analítico de localizá-lo na sua coletânea de produção? Ele é uma continuidade de interesses "antigos" (dada a vasta produção teórica/e de pesquisa que possui) ou representa interesse novo, abordagem nova em relação ao que vinha se dedicando até então?

Gary Herrigel: O artigo tenta fazer um balanço do momento atual da globalização. Basicamente, mapeia como as coisas parecem mudar e mostra quantas das nossas ideias herdadas sobre desenvolvimento, especialização e emprego não fazem um bom trabalho de contabilidade do estado de coisas contemporâneo, pelo menos nas economias políticas avançadas. O meu trabalho utiliza as questões levantadas no artigo como ponto de partida para a investigação atual. Para mim, especificamente, estou a fazer um grande trabalho sobre a história e os processos contemporâneos de recomposição na agricultura.

Gabriela Porcionato: Do seu ponto de vista, quais são os objetos de investigação mais estimulantes que merecem mais investigação nas áreas em que trabalha?

Gary Herrigel: Para mim, as questões de investigação mais prementes hoje em dia envolvem problemas de desigualdade, poder de monopólio, subemprego e degradação econômica. É extremamente importante que se faça investigação

\footnotetext{
${ }^{23}$ Possibilidades industriais e falsa necessidade: repensando a produção, o emprego e a dinâmica do trabalho na economia global (tradução nossa).
} 
sobre estas questões. Na minha opinião, a pauta por soluções para estes problemas aumentará as perspectivas de maior democracia nas economias políticas globais.

Gabriela Porcionato: Qual é o papel das ciências sociais nos problemas atuais do século XXI?

Gary Herrigel: As ciências sociais podem ajudar a identificar as possibilidades que surgem na situação contemporânea. Elas podem fornecer uma perspectiva histórica sobre o presente, que muitas vezes tem o efeito de fazer o que parece inevitável ou natural parecer mais o resultado da ação, interesse e desejo humano. Elas também podem gerar importantes estudos empíricos de dados, conjuntos de dados, reflexões qualitativas e quantitativas sobre processos sociais que permitem a elaboração de políticas mais informadas. Parafraseando Marx, entretanto, é importante ter em mente que os cientistas sociais só interpretam o mundo; os movimentos e forças sociais são os que realmente o mudam.

Gabriela Porcionato: É possível dizer que as ciências sociais estão em crise ou é um momento de fortalecimento?

Gary Herrigel: Em geral, os "especialistas" têm perdido legitimidade no debate público e na sensibilidade. Isto pode não ser tanto por causa de suas ideias, mas pela forma como eles se isolaram da contribuição democrática e da responsabilidade na elaboração de políticas. É verdade que os cientistas sociais não têm sido grandes em prever crises - as que ocorrem parecem ser uma surpresa (a crise financeira, o surgimento de políticas populistas bem sucedidas) e as que são identificadas (desigualdade, encarceramento em massa, etc.) muitas vezes carecem de agentes eficazes para fazer mudanças importantes. A perda de legitimidade dos especialistas e da governança tecnocrática está ligada à degradação da política democrática e ao crescimento das formações oligárquicas em muitos países democráticos liberais. Isso é muito particular para nossa era e é um problema que a ciência social por si só não será capaz de resolver - embora possa contribuir para a reflexão social sobre como resolver o problema. A incapacidade da ciência social de prever as coisas não é realmente particular para o momento presente. É um problema de longa data com a ciência social positivista. Talvez este seja um momento em que tais ambições e concepções epistemológicas possam ser eliminadas e novas formas pós-positivistas de análise social possam florescer. 


\section{REFERÊNCIAS}

FLIGSTEIN, Neil. Habilidade social e a teoria dos campos. Rev. Adm. Empres. São Paulo, v. 47, n. 2, p.61-80, Junho, 2007.

HERRIGEL, Gary. Industrial possibilities and false necessity: rethinking production, employment and labor dynamics in the global economy. Socio-Economic Review, Volume 18, Issue 2, April 2020, p.599-624. Disponível em: https://doi.org/10.1093/ser/mwaa023. Acesso em: 15 abr. 2021.

HERRIGEL, Gary. Interview with SASE President Gary Herrigel. Interview conducted by Georg Rilinger. FEBRUARY 01, 2018. Disponível em: https://sase.org/newsletterwinter-17-18/interview-sase-president-gary-herrigel/. Acesso em: 15 abr. 2021.

HERRIGEL Gary. Manufacturing Possibilities: Creative Action and Industrial Recomposition in the United States, Germany, and Japan. Oxford Scholarship, 2010.

HERRIGEL Gary. Industrial Constructions. The Sources of German Industrial Power. Cambridge: Cambridge University Press, 1996. 